\title{
Optimization of SAE Formula Rear Wing
}

\author{
Jurij Iljaž - Leopold Škerget - Mitja Štrakl - Jure Marn \\ University of Maribor, Faculty of Mechanical Engineering, Slovenia
}

The main goal of this work was to prove the superiority of a slat vs. a second rear flap in the SAE formula rear wing design, combined with a $3 D$ curved rear flap, for low velocities, by optimization of the rear wing design. Two different main designs were compared, with five different height positions of the main wing and complete analysis carried out of the attack angle on wing performance. A numerical approach was used to test the hypothesis with 3D shear stress transport (SST) Reynolds-averaged Navier-Stokes (RANS) simulation, incorporating the whole formula.

A practical use of this work is in designing a rear wing for maximum downforce within the available rules and regulations. It was found that the multi-element wings were suitable for low speeds and that the base design with two flaps should not be positioned too low. The downforce increases with the height of the wing and reaches its maximum value at $8^{\circ}$ angle of attack. For this reason, the new curved design was proposed, including a slat and only one flap. The new wing can cope with a greater angle of attack, has a greater lift coefficient, as well as greater maximal downforce. The advanced design resulted in an increase of downforce of about $6 \%$ at the same wing height.

Keywords: Reynolds-averaged Navier-Stokes equations, rear wing, optimization, computational fluid dynamics, downforce, aerodynamics

Highlights

- Two different designs for multi-section rear wing in SAE formula are presented.

- Several different layouts were analyzed.

- $\quad$ The addition of a slat at the expense of a second flap results in significant increase of downforce (about $6 \%$ ).

- Boundary layer separation causes a significant decrease in lift, and occurs for higher angles of attack in the case of using a slat as opposed to the case without a slat and with the second flap.

\section{INTRODUCTION}

This work deals with taking advantage of the available numerical methods when trying to excel in automotive competition. First, the optimization problem is outlined, to be followed by the proposed numerical solution, as well as the practical consequences of this solution, not as a proof of validity of the numerical approach, but rather as a description of a modern design flow.

Formula SAE is an international competition having the common goal of designing and manufacturing of a racing car. While efforts have been made to keep the average velocity as low as possible, for safety reasons (around $50 \mathrm{~km} / \mathrm{h}$ ), by designing an especially tortuous track, there is fierce competition among competitors. This, rather low, velocity presents an additional challenge before the designer increasing downforce results in higher corner speeds, and this, in turn, leads to better final times during the competition. The design criterion was, therefore, to construct, and manufacture a vehicle which exerted as much downforce as possible.

The body of work related to the rear wings has been performed at Monash University see Wordley and Saunders [1]. However, their work covered 2D computational fluid dynamics (CFD) analysis citing availability of a full-scale wind tunnel. This approach, while completely understandable, is not suitable for those without access to such expensive facilities. We believe and have proven in this work, that similar results can be achieved using full-scale 3D CFD modeling. In addition, we believed that modeling rotating wheels and a moving road were absolutely necessary in order to achieve meaningful results. Also, Wordley and Saunders [1] were not concerned with optimization of height but were rather changing the angle of attack, such approach being understandable for wind tunnel tests.

Doddegowda et al. [2] have also shown generally agreeable computational results without focusing on particular parts of the car. On the contrary, De Silva et al. [3] used CFD for fine-tuning of side panels in order to maximize the use of cooling air. They used moving ground however, not spinning wheels, which, in our opinion, is absolutely necessary to capture the vortex formation around the side walls of the car. The importance of a rotating wheel was, albeit from a different perspective, confirmed by Huminic and Chiru [4].

The surprising scientific result shown herein is that the effect of the slat was more pronounced than the effect of the second flap, for the maximum angle of attack, at the upmost main rear wing position, and this is documented herein. Unfortunately, the final design could not incorporate this result as this would 
have violated the rules relating to the maximum height of the vehicle; one lower position was therefore chosen for the angle of attack analysis. It should be noticed that slat configuration is not used in Formula 1 competition as technical rules [5] specifically prohibit any structure behind the rear wheel centerline comprised of more than two closed sections (Rule 3.10.1.a):

"When viewed from the side of the car, no longitudinal vertical cross-section may have more than two sections in this area, each of which must be closed". No such limitation exists for the SAE formula.

Hence, this work deals with the rear wing optimization of the SAE formula, and its effect on the downforce of the formula. Such an approach requires the existence of a full-scale numerical model of a formula as opposed to only a rear wing model. The model therefore comprises a front, as well as rear wing, undertray with rear diffusor, monocoque including safety cage, side pods, driver, and rotating wheels. Marn and Iljaž [6] have shown that rotating wheels contribute significantly to suction pressure behind the truck trailer, and the same conclusions are (even more) applicable in this case as the wheels for the SAE formula show no enclosure.

To limit the scope of this problem to manageable size we are concerned only with optimization of rear wing, the rest of the model remains the same. Our objective function is total force on the ground as this force is related directly to tire grip and, consequently, the ability of the vehicle to carry more corner speed.

The optimization was performed with CFD using the Reynolds-averaged Navier-Stokes (RANS) shear stress transport (SST) model. The integral parameter deciding the final question was amplitude of the downforce, because even a small increase in downforce is extremely important to the cornering performance of the car. However, the drag was not discontinued or omitted as the numerical simulation was fully $3 \mathrm{D}$. It should also be stated that the power consumption by the drag at these low vehicle speeds was negligible and, therefore, had a very small effect on the acceleration of the car, which is also one of the reasons why the drag was neglected in the design evaluation.

Literature search reveals that in addition to Wordley and Saunders [1], Venkatesan et al. [7] report on wing profiles and ground effect in cars, $\mathrm{Hu}$ and Wong [8] report on the rear wing effect on a personal vehicle, and Kieffer et al. [9] report on front and rear wings in Formula Mazda. It should be stressed, however, that the latter works are only concerned with high speeds, which is not applicable in this case. A comprehensive study was performed by Jensen, [10] who was concerned with undertray analysis. None of the studies found were concerned with 3D rear wing optimization varying distance from the ground, and/or comparing effects of slat vs. second flap.

The results of Wordley and Saunders [1] prove that $2 \mathrm{D}$ analysis is, basically, useful only for prediction of general behavior. Huminic and Chiru [4] prove that it is necessary to model spinning wheels as well as a rolling road. In order to compose a suitable model we must therefore explore full 3D analysis, with moving road and spinning wheels, in addition to varying parameters such as distance of rear wing from the ground and angle of attack, as well as adding of a slat in front of the main wing in the rear wing assembly.

Based on the foregoing we explored some more general studies in order to get an insight into neighboring studies.

Zvar Baskovic et al. [11] investigated the use of different turbulence models with different treatment near the wall to do RANS simulation of adiabatic flow in an air-conditioned vehicle compartment. Their findings are that SST $k-\omega$ model provides the best overall performance, despite the needed evaluation.

Bizjan et al. [12] tested a flow image Velocimetry method based on advection-diffusion equation, on a much simpler airfoil than ours and compared the results with the CFD RANS simulation. They found that the used SST model provides good agreement with measured data for mean flow and that the used Velocimetry method is in good agreement with the true velocity field. The paper also shows a promising way of developing a new optical flow measurement method for aerodynamic.

Jošt et al. [13] also discussed about the appropriate turbulence model for Kaplan turbine, where the RANS-SST model showed significantly better results than the usually used $k-\varepsilon$ turbulence model.

In addition, the above referenced CFD studies only referred to straight wings (without 3D curvature) our advance design is also concerned with 3D curvature of the main wing and rear flap just to increase the angle of attack at both sides, to gain some downforce of the undisturbed flow which will be discussed later.

\section{BASIC AND ADVANCED DESIGNS}

Basic and advanced designs are shown in Figs. 1, and 2 , respectively.

In the past the aerodynamic theory was first developed for airplanes. As no or very limited 
computational tools were available, general equations were developed in order to compare different designs quickly. Aerodynamic force reads ([14] and [15]):

$$
F_{i}=\frac{1}{2} \cdot C_{i} \cdot \rho \cdot A \cdot v^{2},
$$

where $F_{i}$ is horizontal or vertical aerodynamic force ( $F_{L}$ represents lift or downforce and $F_{D}$ drag), $\rho$ fluid density, $A$ characteristic surface area, $v$ characteristic velocity, and $C_{i}$ aerodynamic coefficient $\left(C_{L}\right.$ represents lift and $C_{D}$ drag coefficient). In our case negative lift force is produced by the wing, and called downforce; the force with which the tires press onto the surface. Without the downforce the highest lateral acceleration of a car possible to withstand is around $g$. Tight curves cause an acceleration component in a radial direction to exceed $g$ quickly resulting in underor oversteering of a vehicle.

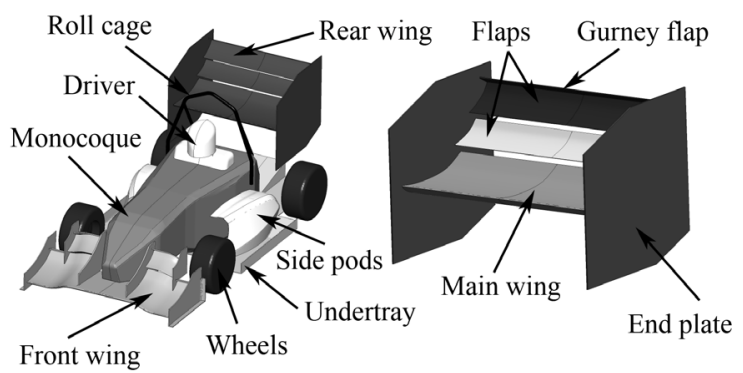

Fig. 1. Basic design

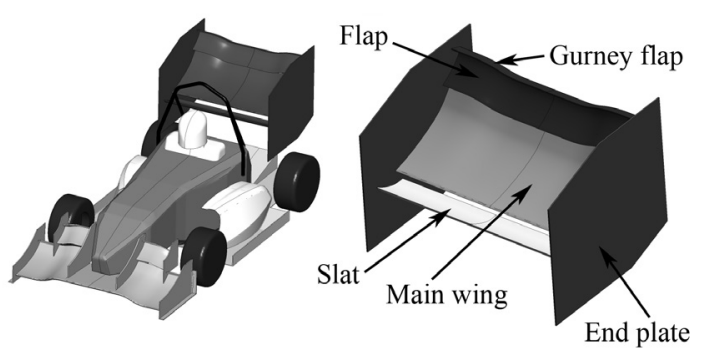

Fig. 2. Advanced design

This aerodynamic force can be increased by increasing any of the right-hand side components of Eq. (1). As density and velocity variations (fluid is air, velocity is low) are limited, the only components remaining are surface area and lift coefficient. The obvious variation, the surface area of the wing is limited by regulations. Current SAE regulations [16] limit the wing not to exceed $1.2 \mathrm{~m}$ distance from the ground, being wider than the distance between the inner sides of the rear wheels, or exceeding $250 \mathrm{~mm}$ in length measured from the end of the rear wheels. Of course, increasing the surface area to maximum makes sense but the real challenge is to construct a wing which would increase the lift coefficient beyond current, and readily available designs.

There are limitations, of course. Wordley and Saunders [1] present convincing arguments showing that, in general, the angle of attack increases downforce up to the point of stalling (flow separation). To prevent this, the wing was separated in several sections (main wing, flaps, slats etc.). It is well known that single section wings achieve $C_{L} \approx 1$, while multiple section wings arrive at much higher lift coefficients, i.e. $C_{L} \approx 2$ to 3 due to larger curvature of the wing and angle of attack (Katz [14] and [15] and McBeath [17]). As a consequence, we decided to use a three section rear wing as a compromise between manufacturing capabilities having sufficient material strength, and increased angle of attack.

In order to arrive at a qualitative solution of multi-element airfoil profile we had to perform simplified analysis due to the lack of actual data in open literature. First, we used 2D computations taking advantage of the potential flow based computer code JavaFoil 2.18 which simulates an arbitrary profile, including a multi-section one. For the basic profile, a NACA 63A-2010 was chosen with the flap presenting $33 \%$ of the main wing surface area, and overlap of sections of about $6 \%$. After that, we evaluated the design multi-element airfoil profile with 2D SST RANS simulation using Ansys CFX 15.0 computer code.

The last step was a set of full 3D calculations of the airfoil profile to arrive at the basic design of rear wing composed of a main wing, two flaps, end plates and Gurney flap attached to the last section. The wing is $970 \mathrm{~mm}$ long and $710 \mathrm{~mm}$ wide.

Granted, the wing looks much different from what we are accustomed to from Formula 1 or sports cars design, but the difference is in the different treatment of Eq. (1) in Formula 1 (and in the sports car business) the downforce is increased by increasing the velocity and not the surface area, or lift coefficient as in the present case.

For the advance design, we exchanged the last section (second flap) with a slat in front of the main wing, as can be seen from Figs. 1 and 2.

The flaps prevent flow separation and turn flow upward to simulate a larger angle of attack. The slat feeds flow below the main wing in order to prevent stalling, enabling the main wing to attain a higher angle of attack. 


\section{GOVERNING EQUATIONS}

In order to solve the problem at hand the following well-known governing equations were solved [18]. Mass conservation equation:

$$
\frac{\partial \rho}{\partial t}+\nabla \cdot(\rho \mathbf{v})=0
$$

where $\rho$ is density, $t$ is time, $\nabla$ gradient, $\nabla$. divergence and $\mathbf{v}$ velocity. Momentum conservation can be written as:

$$
\rho\left[\frac{\partial \mathbf{v}}{\partial t}+(\mathbf{v} \cdot \nabla) \mathbf{v}\right]=\rho \cdot \boldsymbol{f}_{m}-\nabla p+\nabla \cdot \tau,
$$

where $\boldsymbol{f}_{m}$ is body force, $p$ pressure and $\boldsymbol{\tau}$ stress tensor. Taking account for Newtonian fluids having symmetry of stress tensor in mind:

$$
\tau=\eta\left(2 \nabla \mathbf{v}-\frac{2}{3} \delta \nabla \cdot \mathbf{v}\right),
$$

where $\eta$ is dynamic viscosity and $\delta$ is Kronecker delta function without units.

Turbulence was modeled using $k-\omega$ based SST model. $k-\omega$ model links turbulence kinetic energy $k$ and its frequency $\omega$ via the relation:

$$
\eta_{t}=\rho \frac{k}{\omega}
$$

where $\eta_{t}$ is turbulence viscosity and $\rho$ fluid density. Two transport equations, for turbulence kinetic energy and its frequency, were modeled by Wilcox [19] in the following terms:

$$
\begin{gathered}
\frac{\partial(\rho k)}{\partial t}+\nabla(\rho \mathbf{v} k)= \\
=\nabla\left[\left(\eta+\frac{\eta_{t}}{\sigma_{k}}\right) \nabla k\right]+P_{k}-\beta^{\prime} \rho k \omega+P_{k b}, \\
\frac{\partial(\rho \omega)}{\partial t}+\nabla(\rho \mathbf{v} \omega)= \\
=\nabla\left[\left(\eta+\frac{\eta_{t}}{\sigma_{\omega}}\right) \nabla \omega\right]+\alpha \frac{\omega}{k} P_{k}-\beta^{\prime} \rho \omega^{2}+P_{\omega b},
\end{gathered}
$$

where $\alpha, \beta^{\prime}, \sigma_{k}$ and $\sigma_{\omega}$ are model constants. The stress tensor is then computed from the Eddy viscosity concept.

The SST model implements a limiter to the formulation of Eddy viscosity, and decreases its over prediction, due to not accounting for the transport of turbulent shear stress. Limited Eddy viscosity is formulated in following form:

$$
v_{t}=\frac{a_{1} k}{\max \left(a_{1} \omega, S F_{2}\right)}
$$

where $a_{1}$ is a model constant, $v_{t}=\eta_{t} / \rho$ turbulence kinematic viscosity, $F_{2}$ is a blending function which restricts the limiter to the wall boundary layer and $S$ is an invariant measure of the strain rate.

\section{NUMERICAL MODEL}

A commercial 3D CFD solver, Ansys CFX 15.0, was used for solving the above referenced governing equations. While we were only concerned with the rear wing, the whole SAE formula was modeled, including rotating wheels. This approach enables a designer to "freeze" the best design of a particular element, and adjusts the other aerodynamic element in order to arrive at the best solution.

Conceptually the governing equations can be treated as parabolic although in fact they are not, but contribution of the upstream flow disturbance is far lower than downstream. This also means that the effect of design changes made on the rear wing will not propagate upstream strongly enough to have an important effect on the front wing or undertray. Therefore, ideally, one would start with designing of the front wing, followed by side pods, undertray, and finally the rear wing.

We have used RANS-SST simulation. Other turbulence models could be used but we opted for SST as we believe that it describes turbulence better close to the wall and allows for better prediction of boundary layer separation, and this, in turn, results in a better description of the recirculation zone and overall downforce. Galilean transformation was applied, and wheels were assumed to rotate with appropriate velocity.

Simplification of the problem is in assuming that the vehicle is moving straight forward. While turning would not have presented significant additional computational effort and would far better describe actual conditions on track such results would be hardly comparable to any other published results.

The numerical domain is seen in Fig. 3 and it is comprised of a vehicle representing the SAE formula, and its immediate environment. The domain is split symmetrically under the assumption that, as no cross wind is modelled, the results should be symmetrical. Strictly speaking, this is not entirely so; vortex shedding may occur alternately. However, as computation was in a steady state, this assumption was considered acceptable. In order to prevent wall effects the computational domain was $16.4 \mathrm{~m}$ in 
length, $5.8 \mathrm{~m}$ in width (double width), and $4.5 \mathrm{~m}$ in height. The outer dimensions of SAE formula were $2.8 \mathrm{~m}$ in length, $1.4 \mathrm{~m}$ in width, and $1.2 \mathrm{~m}$ in height; about five length of car was modeled after the vehicle.

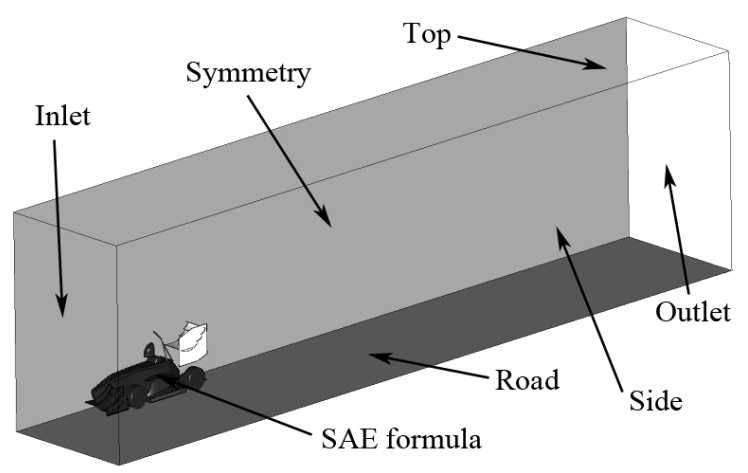

Fig. 3. Computational domain

The speed of the vehicle was $14 \mathrm{~m} / \mathrm{s}$ which corresponds to $50 \mathrm{~km} / \mathrm{h}$ which is average velocity during the competition. Boundary conditions were uniform flow at the entrance into the computational domain (inlet), open boundary condition (pressure $0 \mathrm{~Pa}$ ) at the exit out of the computational domain (outlet), slip boundary condition on the top and side wall, symmetry boundary condition at the symmetry border, and no-slip boundary condition on the moving road with the speed of the vehicle.

No-slip boundary condition was present throughout the formula's surfaces with the exception of the wheels. Wheels were assumed smooth, and were assumed to rotate with constant velocity - this velocity was $61.4 \mathrm{rad} / \mathrm{s}$ for wheels with an outer diameter of $456.8 \mathrm{~mm}$.

Non-structured mesh was used for discretization of the computational domain, and particular effort was paid to discretization of wings and other aerodynamically relevant elements. Computational mesh was generated with the commercial package ICEM CFD 15.0.

In order to achieve comparable results, mesh and domain analyzes should be performed. The mesh analyze is presented in Tables 1 and 2, and domain analyze in Table 3 . We compared the produced downforce and drag of the rear wing among different mesh and domain sizes.

Mesh size was varied between about 2.2 million elements to about 14.4 million elements, distributed among various parts of the vehicle and environment (see Table 1), and domain size (Fig. 3) was varied between box length of $8.4 \mathrm{~m}$ to $16.4 \mathrm{~m}$, box half-width of $1.5 \mathrm{~m}$ to $2.9 \mathrm{~m}$, and box height of $3 \mathrm{~m}$ to $4.5 \mathrm{~m}$.
In order to perform mesh analyze we had to fix domain size, and check for the parameter value varying mesh size. We fixed domain size at D3 (i.e. $10.4 \mathrm{~m}$ in length, $2.4 \mathrm{~m}$ in half-width and $4 \mathrm{~m}$ in height). We actually observed five predetermined parameters, namely forces on main wing, on flaps 1 and 2 , downforce on the rear wing and drag, respectively. Table 2 shows that while force on main wing was increasing monotonously, the forces on the flaps were oscillating around the same value. However, we can observe the convergence of the downforce and drag of the rear wing. Based on this, and taking into account available resources we decided on mesh $\mathrm{m} 3$.

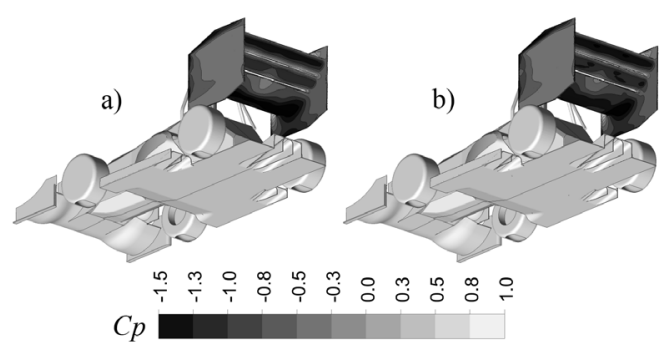

Fig. 4. Pressure distribution over rear wing (bottom side): a) $m 3$, and b) $m 4$

Fig. 4 shows the qualitative difference between meshes, showing the pressure coefficient $C_{P}$ (Katz [14] and [15]). We observed that the difference between most fine meshes was minimal; looking globally the pressure distribution was the same.

After the decision to use mesh m3 was made, we focused on domain size analyze. Varying the box size, we found that downforce and drag of the rear wing converged with increasing domain size and that there was small variance between the domain D4 and D5 (see Table 3). However, we decided to go with the largest box size, as the increase was not prohibitive.

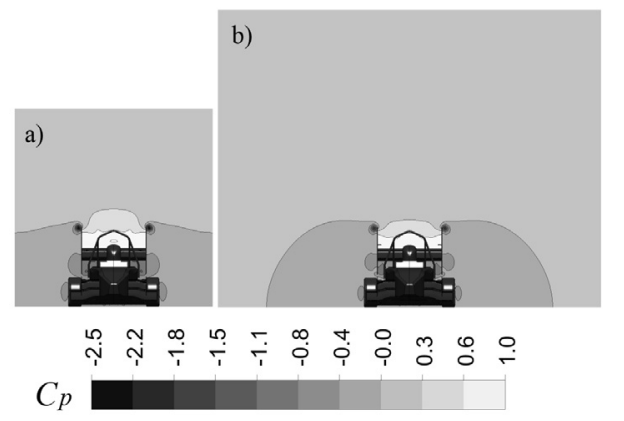

Fig. 5. Pressure field: a) D1, and b) D5

Fig. 5 shows clearly the reason for the variation. From Fig 5a one can observe that the isobars intersect 
Table 1. Mesh properties

\begin{tabular}{|c|c|c|c|c|c|}
\hline Element size [mm] & $\mathrm{m} 0$ & $\mathrm{~m} 1$ & $\mathrm{~m} 2$ & $\mathrm{~m} 3$ & $\mathrm{~m} 4$ \\
\hline Monocoque & 40 & 32 & 25 & 20 & 16 \\
\hline Wing & 24 & 19 & 15 & 12 & 10 \\
\hline Undertray & 40 & 32 & 25 & 20 & 16 \\
\hline Road & 90 & 72 & 57 & 45 & 36 \\
\hline Cage & 12 & 9.5 & 7.5 & 6 & 5 \\
\hline Air & 240 & 190 & 150 & 120 & 100 \\
\hline Surroundings & 120 & 95 & 75 & 60 & 50 \\
\hline Number of elements & $2,246,162$ & $3,629,026$ & $5,084,677$ & $9,702,520$ & $14,409,563$ \\
\hline Number of nodes & 516,806 & 822,227 & $1,097,061$ & $2,152,744$ & $3,252,490$ \\
\hline
\end{tabular}

Table 2. Mesh analyze on domain D3

\begin{tabular}{lrrrrr}
\hline Mesh analisys & $\mathrm{m} 0$ & $\mathrm{~m} 1$ & $\mathrm{~m} 2$ & $\mathrm{~m} 3$ & $\mathrm{~m} 4$ \\
\hline$F_{\text {main }}[\mathrm{N}]$ & 55.3 & 71.0 & 86.0 & 89.8 & 90.8 \\
\hline$F_{\text {flap } 1}[\mathrm{~N}]$ & 24.4 & 26.2 & 24.5 & 28.8 & 28.5 \\
\hline$F_{\text {flap } 2}[\mathrm{~N}]$ & 13.8 & 15.2 & 14.9 & 15.0 & 16.2 \\
\hline$F_{D W N}[\mathrm{~N}]$ & 93.3 & 112.2 & 125.2 & 133.4 & 134.8 \\
\hline$F_{D R A G}[\mathrm{~N}]$ & 53.0 & 57.0 & 57.0 & 61.1 & 61.6 \\
\hline
\end{tabular}

with the border of the domain meaning that borders were actually treated as walls. The Fig. 5b shows correct pressure field distribution, hence the decision for D5 domain size. Mesh and domain analyze showed a variation of parameter value, which was not strictly monotonic.

The absence of monotonic change (either increase or decrease) is considered as a telltale that changes are no longer dependent on mesh or domain size and that further increase in node numbers or decrease in mesh size on one hand or further increase in domain size on the other hand do not yield desirable results.

Based on these results, the mesh $\mathrm{m} 3$ on the domain D5 with 12,484,513 elements was used, with lower aspects ratios close to the SAE formula boundary, and higher aspect ratios away. The ratio between the largest and smallest elements was about $10: 1$.

\section{RESULTS AND DISCUSSION}

First, basic design was analyzed. The results are summarized in Tables 4 and 5 for the effect of main wing height (distance from ground) and angle of attack, respectively.

We fixed the angle of attack at $10^{\circ}$ and varied the main wing distance from the ground in order to find the dependence of various forces on rear wing parts on this variation. The results are presented in Table 4 and Fig. 6. The conclusion here is that the rear wing should be positioned as high as possible, to minimize the effect of other elements like driver, monocoque etc.

Based on these results, and taking note of regulation height limitation, along with the existence of two flaps after the main wing, we decided for the maximum height of $760 \mathrm{~mm}$. This also allowed us to increase the angle of attack slightly, and to stay within the regulation window. The next parameter which could be varied was the angle of attack (AOA). The results are summarized in Table 5 and Fig. 7. We decreased the angle step around the maximum performance angle, to see the stalling point. The stalling occurs at $11^{\circ}$ for a height of $760 \mathrm{~mm}$.

Taking downforce as a deciding factor, we concluded that the best scenario for base design is high main wing position $(760 \mathrm{~mm})$ and an $8^{\circ}$ angle of attack.

Table 3. Domain analyze

\begin{tabular}{lccccc}
\hline \multirow{2}{*}{ Domain size $[\mathrm{m}]$} & $\mathrm{D} 1$ & $\mathrm{D} 2$ & $\mathrm{D} 3$ & $\mathrm{D} 4$ & $\mathrm{D}$ \\
\cline { 2 - 6 } & $8.4 / 1.5 / 3.0$ & $9.4 / 1.9 / 3.5$ & $10.4 / 2.4 / 4.0$ & $11.4 / 2.9 / 4.5$ & $16.4 / 2.9 / 4.5$ \\
\hline$F_{\text {main }}[\mathrm{N}]$ & 113.0 & 101.6 & 89.8 & 92.6 & 93.8 \\
\hline$F_{\text {flap } 1}[\mathrm{~N}]$ & 31.1 & 28.5 & 28.8 & 25.5 & 23.8 \\
\hline$F_{\text {flap } 2}[\mathrm{~N}]$ & 16.5 & 15.3 & 15.0 & 14.5 & 14.1 \\
\hline$F_{D W N}[\mathrm{~N}]$ & 160.4 & 145.3 & 133.4 & 132.6 & 131.5 \\
\hline$F_{D R A G}[\mathrm{~N}]$ & 69.5 & 63.5 & 61.1 & 58.0 & 56.1 \\
\hline
\end{tabular}


The notations in the graphs in Figs. 6 and 7 show "base" for basic design, "CL" for lift coefficient, "CD" for drag coefficient, "advanced" for advanced design and "no-fw" for no-front-wing construction.

Table 4. Effect of rear wing height for basic design $\left(10^{\circ} \mathrm{AOA}\right)$

\begin{tabular}{lrrrrr}
\hline$h$ [mm] & \multicolumn{1}{c}{670} & \multicolumn{1}{c}{700} & \multicolumn{1}{c}{730} & \multicolumn{1}{c}{760} & \multicolumn{1}{c}{790} \\
\hline$F_{\text {main }}[\mathrm{N}]$ & 76.5 & 93.8 & 95.8 & 112.5 & 121.41 \\
\hline$F_{\text {flap } 1}[\mathrm{~N}]$ & 25.8 & 23.8 & 29.5 & 30.0 & 30.8 \\
\hline$F_{\text {flap } 2}[\mathrm{~N}]$ & 14.6 & 14.1 & 15.4 & 18.3 & 16.0 \\
\hline$F_{D W N}[\mathrm{~N}]$ & 116.6 & 131.5 & 140.7 & 160.9 & 168.3 \\
\hline$F_{D R A G}[\mathrm{~N}]$ & 54.9 & 56.1 & 59.6 & 63.2 & 66.8 \\
\hline
\end{tabular}

In order to explain the reasons better several figures are presented. Fig. 8 shows pressure field

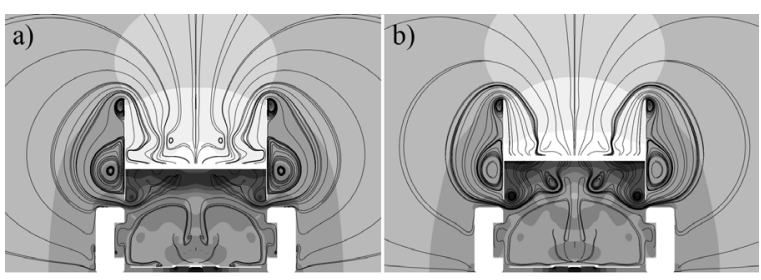

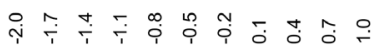

$C_{p}$

Fig. 8. Pressure field for base wing: a) $700 \mathrm{~mm}$, and b) $760 \mathrm{~mm}$

Table 5. Effect of AOA for basic design $(760 \mathrm{~mm})$

\begin{tabular}{|c|c|c|c|c|c|c|c|c|c|c|}
\hline $\mathrm{AOA}\left[^{\circ}\right]$ & 0 & 4 & 7 & 8 & 9 & 10 & 11 & 12 & 13 & 16 \\
\hline$F_{\text {main }}[\mathrm{N}]$ & 91.3 & 98.5 & 113.0 & 114.9 & 113.1 & 112.5 & 89.8 & 95.8 & 82.5 & 82.0 \\
\hline$F_{\text {flap } 1}[\mathrm{~N}]$ & 29.2 & 28.9 & 30.0 & 29.8 & 30.1 & 30.0 & 30.9 & 30.2 & 32.3 & 28.5 \\
\hline$F_{\text {flap2 }}[\mathrm{N}]$ & 21.2 & 19.3 & 18.2 & 17.5 & 17.9 & 18.3 & 13.9 & 13.6 & 14.6 & 12.7 \\
\hline$F_{D W N}[\mathrm{~N}]$ & 141.5 & 159.1 & 161.4 & 162.4 & 161.1 & 160.9 & 134.3 & 139.4 & 128.9 & 122.6 \\
\hline$F_{D R A G}[\mathrm{~N}]$ & 40.7 & 53.9 & 56.0 & 58.3 & 61.3 & 63.2 & 66.1 & 70.9 & 74.4 & 78.1 \\
\hline
\end{tabular}

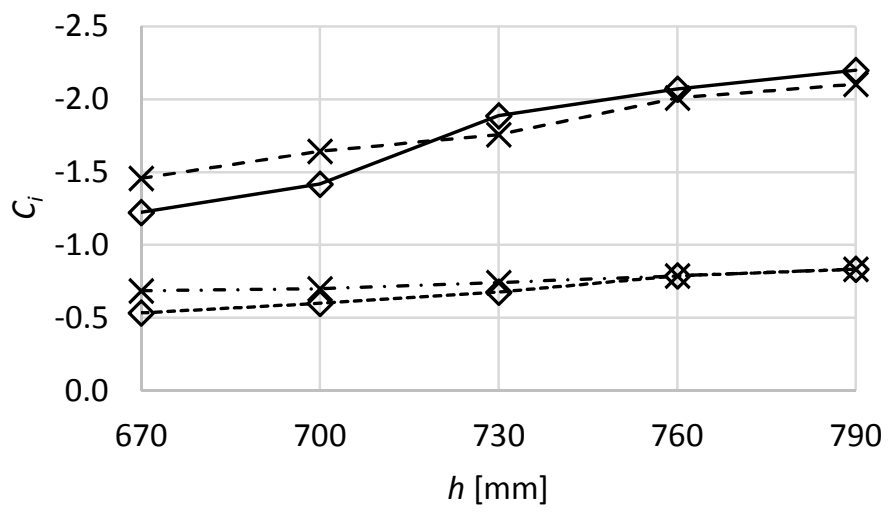

$--x-$ base-CL

- $\times$ - base-CD

$\curlyvee$ advanced-CL

--»-- advanced-CD

Fig. 6. Lift and drag coefficients as functions of height

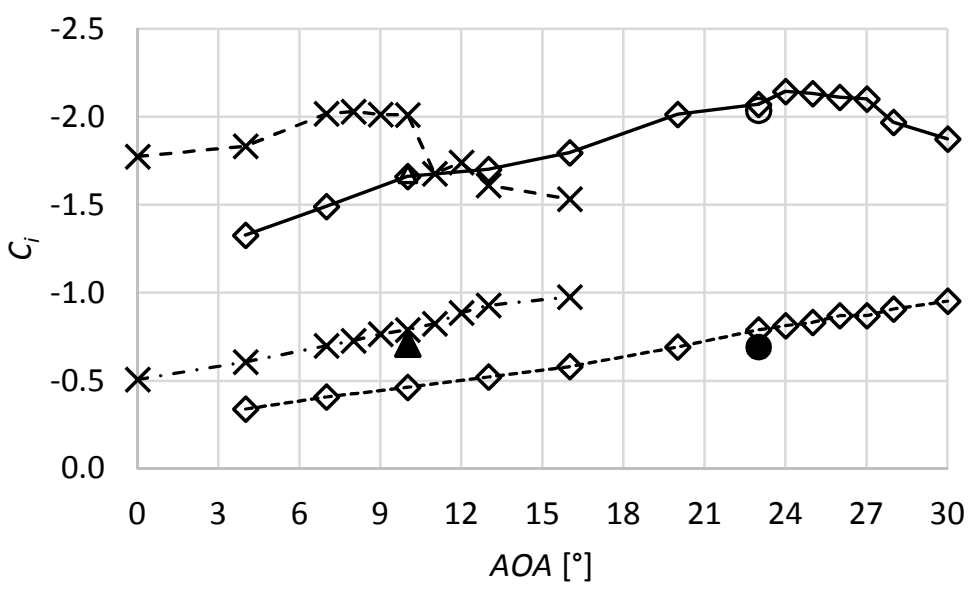

$--X-$ base-CL

$-\cdot \times \cdot$ - base-CD

$\diamond$ advanced-CL

--•-- advanced-CD

$\Delta$ no-fw base CL

$\Delta$ no-fw base-CD

O no-fw advanced-CL

- no-fw advanced-CD

Fig. 7. Lift and drag coefficients as functions of $A O A$ 
variation with plotted streamlines. One can see the development of side vortices and decreased static pressure under the wing with increased height. We can also observe several vortices, especially on the top of the end plate, producing low-pressure region inside the center, which reflects the strength of vortex.

Fig. 9 shows the positive effect of increasing the height of the main wing on the reduced effect of recirculation; the smaller the recirculation region beneath the rear wing, the better the ride.

Fig. 10 presents the pressure field difference between the optimal angle of attack $8^{\circ}$, and at the $13^{\circ}$ angle, when the stalling occurs. The low end plate vortices are much stronger for the former resulting in lower static pressure at the bottom and consequently higher downforce.

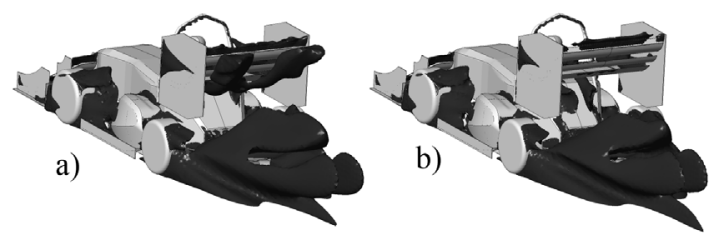

Fig. 9. Recirculation behind base rear wing: a) $700 \mathrm{~mm}$, and b) $760 \mathrm{~mm}$

Fig. 11 shows, on the other hand, the negative impact of an increasing angle of attack indiscriminately, showing isosurface of recirculation. The increased angle of attack resulted in stalling; the production of a recirculation region beneath the rear wing, which increased the drag and reduced the downforce drastically.

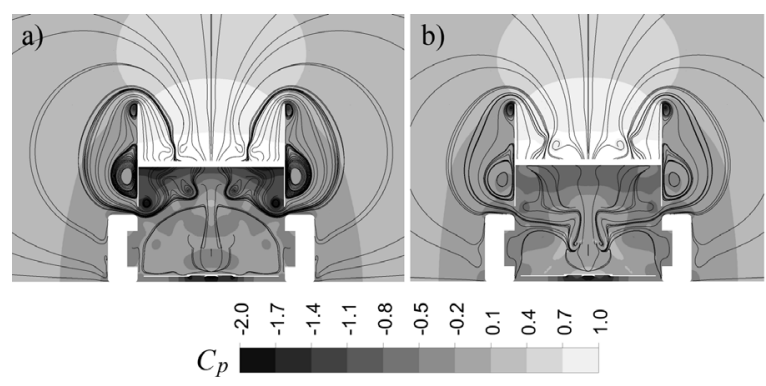

Fig. 10. Pressure field for base wing: a) $A O A 8^{\circ}$, and b) $A O A 13^{\circ}$

Last, but not least, we compared the effect of the front wing. Fig. 12 shows the absence of front wing for base design and $10^{\circ} \mathrm{AOA}$. The absence of a front wing eliminates some of the low end-plate vortices and reduces the low static pressure under the wing, which means that the downforce is far smaller, and effects of such change undesirable. The effect of the front wing is much stronger for the base design than for the advanced, as can be seen from the graph in Fig. 7.

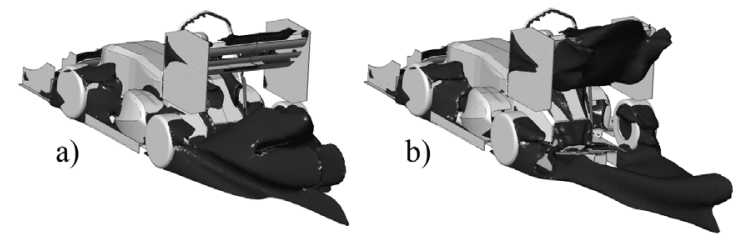

Fig. 11. Recirculation behind base rear wing: a) $A O A 8^{\circ}$, and b) $A O A 13^{\circ}$

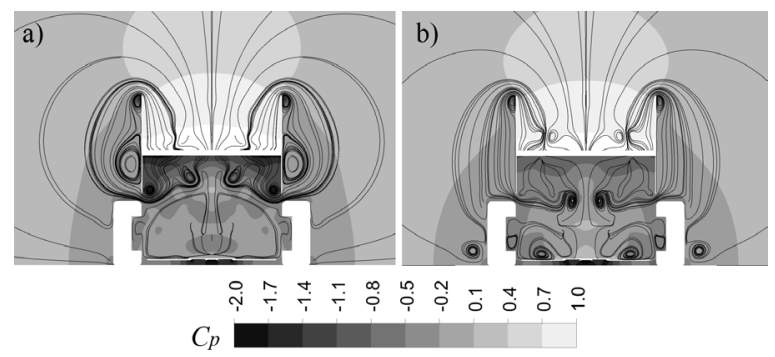

Fig. 12. Pressure field: a) with, and b) without front wing

The downforce manifests itself with the formation of side vortices (which is also the main reason why 2D simulation lacked comparison with the experimental data as side vortices are a 3D phenomenon resulting from twisting and stretching term and could not have been predicted with a $2 \mathrm{D}$ simulation.

Similar analyze of the advanced design as for that of the basic one yields the results as summarized in Tables 6 and 7, for the effect of main wing height at $23^{\circ} \mathrm{AOA}$ and main wing angle of attack at height $760 \mathrm{~mm}$, respectively. The results are also presented in Figs. 6 and 7, showing the drag and lift coefficient.

Table 6. Effect of height for advanced design $\left(23^{\circ} \mathrm{AOA}\right)$

\begin{tabular}{lccccc}
\hline$h$ [mm] & 670 & 700 & 730 & 760 & 790 \\
\hline$F_{\text {main }}[\mathrm{N}]$ & 61.9 & 72.8 & 89.7 & 104.4 & 111.8 \\
\hline$F_{\text {flap } 1}[\mathrm{~N}]$ & 22.9 & 27.6 & 42.9 & 43.9 & 47.5 \\
\hline$F_{\text {flap } 2}[\mathrm{~N}]$ & 13.3 & 13.1 & 18.2 & 17.3 & 16.5 \\
\hline$F_{D W N}[\mathrm{~N}]$ & 97.9 & 113.4 & 150.9 & 165.7 & 175.8 \\
\hline$F_{D R A G}[\mathrm{~N}]$ & 42.8 & 48.0 & 54.3 & 63.2 & 66.9 \\
\hline
\end{tabular}

As can be seen from Fig. 7, the basic design suffers from boundary layer separation very early on despite the trend increasing both lift, and drag with increasing angle of attack. This is where the slat comes into play (advanced design). The slat enables much higher angles of attack, which, in turn, increases the formation of side vortices, and they in turn increase total downforce. The logical conclusion (tested, to affirmative, yet not presented herein) is that 
Table 7. Effect of angle of attack for advanced design $(760 \mathrm{~mm})$

\begin{tabular}{lccccccccccc}
\hline AOA $\left[^{\circ}\right]$ & 10 & 13 & 16 & 20 & 23 & 24 & 25 & 26 & 27 & 28 & 30 \\
\hline$F_{\text {main }}[\mathrm{N}]$ & 91.1 & 91.9 & 94.6 & 103.4 & 104.4 & 107.7 & 105.8 & 104.5 & 104.7 & 95.4 & 92.4 \\
\hline$F_{\text {flap } 1}[\mathrm{~N}]$ & 20.9 & 25.0 & 30.7 & 40.2 & 43.9 & 47.6 & 48.3 & 47.7 & 49.2 & 45.7 & 43.3 \\
\hline$F_{\text {flap } 2[\mathrm{~N}]}$ & 20.7 & 19.0 & 18.2 & 17.3 & 17.3 & 16.3 & 16.3 & 16.5 & 14.1 & 16.4 & 14.3 \\
\hline$F_{D W N}[\mathrm{~N}]$ & 132.8 & 136.1 & 143.6 & 161.1 & 165.7 & 171.6 & 170.5 & 168.8 & 168.2 & 157.5 & 150.0 \\
\hline$F_{D R A G}[\mathrm{~N}]$ & 37.0 & 41.7 & 46.6 & 55.5 & 63.2 & 65.0 & 66.6 & 69.6 & 69.7 & 72.7 & 76.2 \\
\hline
\end{tabular}

adding additional flap (and violating SAE formula rules) would increase downforce further.

But, also the advanced design is not immune to boundary layer separation which is observed in AOA above $27^{\circ}$. A further increase of AOA results in a decrease in lift, behavior similar to Fig. 11b, formation of recirculation region beneath the rear wing.

While it may be counter intuitive that we are still constrained with $760 \mathrm{~mm}$, this is not so. Namely, the addition of the slat results in a much higher angle of attack, which, in turn, presents the same constraints in height.

The formation of top end-plate side vortices is seen nicely in Fig. 13 for the advanced design at optimal AOA showing streamlines.

Based on these findings we found the best results for advanced design were a height of $760 \mathrm{~mm}$, and $24^{\circ}$ AOA. This coincides with the wind tunnel measurement supported findings of Wordley and Saunders [1]; of course qualitatively, as quantitative measurements depend on actual wing setup, which was completely different in this case.

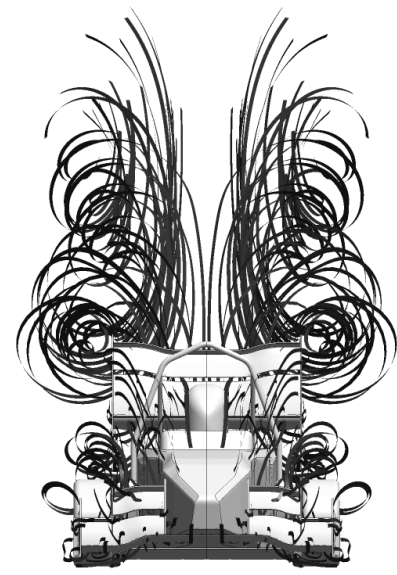

Fig. 13. Streamline formation

Comparing basic and advanced design we found that eliminating the second flap in favor of a slat, which in turn enables an increasing angle of attack, results in an increase of downforce from $162.4 \mathrm{~N}$ to 171.6 N, or an almost $6 \%$ increase! The difference between the base and advanced design at optimal AOA can be also seen from Fig. 14.

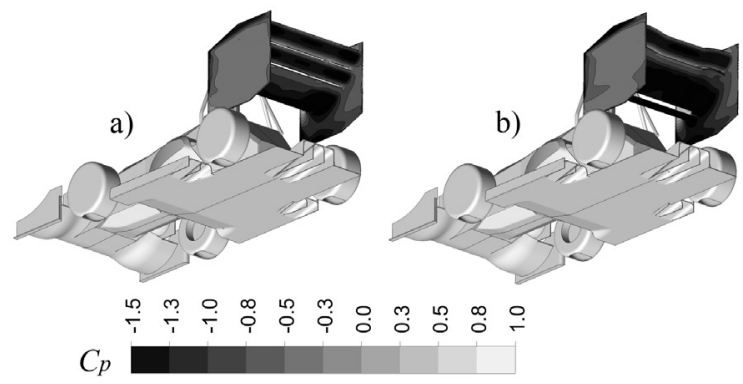

Fig. 14. Pressure field for a) base, and b) advanced design

We conclude that for SAE formula to function in optimum regime, the angle of attack should be as high as possible, with wing height also as high as possible. Our greatest fear of rapid boundary layer separation at increased AOA, resulting in drastic reduction of downforce for advanced design, did not materialize.

As a final note, we wish to emphasize that this wing was actually used on track resulting in the $1^{\text {st }}$ position in skidpad (i.e. lateral acceleration), and $1^{\text {st }}$ position in autocross qualification at most race track in the Czech Republic (Fig. 15).

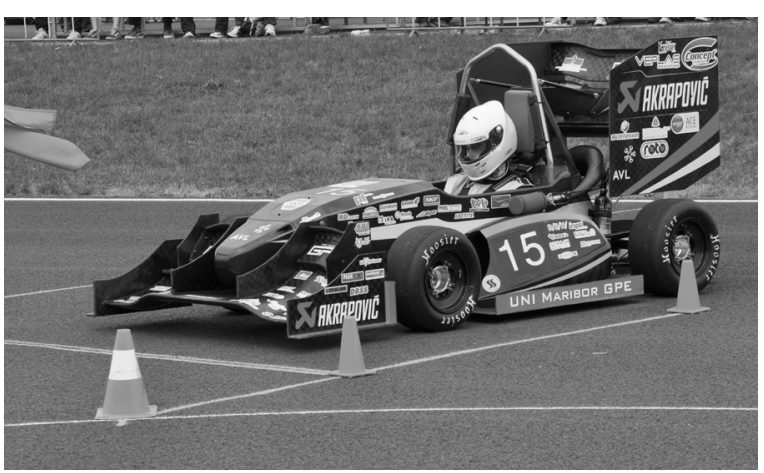

Fig. 15. Most race track in 2015

Especially, the skidpad competition is a direct result of a downforce exerted enabling the vehicle to carry high corner speed, which was the aim of this investigation in the first place. 


\section{CONCLUSIONS}

During development of the model there were several lessons learned. First, multi-section wings can be simulated successfully using full-scale 3D numerical modeling, along with SST turbulent flow model, spinning wheels and moving road.

Next, flow separation is the main problem to be expected for development of a rear wing. This problem can be fixed by adding a slat before the main wing instead of the second flap after the first flap.

There is no need to keep main wing basically extruded 2D profile. The 3D wing variation improved results by adding an anti-yaw effect to the end plates.

End plates are as important as a front wing. Without either the side vortices are not developed, and the flow is swept downstream in the form of twistingand-stretching vortices after the rear wing; while the former increase downforce the latter reduce it.

Provided that flow separation can be avoided, a higher angle of attack and higher main wing position generally lead to higher downforce. However, once flow separation occurs, the effects are immediate, and detrimental.

The main effect of the advanced design is increased downforce and lower sensitivity to sudden flow separation at high AOA, which results in better overall performance.

\section{REFERENCES}

[1] Wordley, S., Saunders, J. (2006). Aerodynamics for formula SAE: A numerical wind tunnel and on-track study. SAE Technical Paper, no. 2006-01-0808, Dol:10.4271/2006-010808.

[2] Doddegowda, P., Bychkovsky, A., George, A. (2006). Use of computational fluid dynamics for the design of formula SAE race car aerodynamics. SAE Technical Paper, no. 2006-010807, D0I:10.4271/2006-01-0807.

[3] De Silva, C.M., Nor Azmi, M., Christie, T., Abou-saba, E., Ooi, A. (2011). Computational flow modelling of formula-SAE sidepods for optimum radiator heat management. Journal of Engineering Science and Technology, vol. 6, no. 1, p. 94-108.

[4] Huminic, A., Chiru, A. (2006). On CFD investigations of vehicle aerodynamics with rotating wheels simulation. SAE Technical Paper, no. 2006-01-0804, D0l:10.4271/2006-01-0804.
[5] F 1 Technical Regulations. (2014). FIA, from http://www. fia.com/sites/default/files/regulation/file/2015\%20 TECHNICAL\%20REGULATIONS\%202014-12-03.pdf, accessed on 2015-11-05.

[6] Marn, J., Iljaž, J. (2014). Effect of wheels on flow around truck trailer. Acta Hydrotehnica, vol. 27, no. 46, p. 29-41.

[7] Venkatesan, D.V., Sanjay, K.E., Sujith Kumar, H., Abhilash, N.A., Ashwin Ram, D., Sanal Kumar, V.R. (2014). Studies on race car aerodynamics at wing in ground effect. International Journal of Mechanical, Aerospace, Industrial, Mechatronic and Manufacturing Engineering, vol. 8, no. 7, p. 1169-1174.

[8] Hu, X.X., Wong, E.T.T. (2011). A numerical study on rear-spoiler of passenger vehicle. International Journal of Mechanical, Aerospace, Industrial, Mechatronic and Manufacturing Engineering, vol. 5, no. 9, p. 1800-1805.

[9] Kieffer, W., Moujaes, S., Armbya, N. (2006). CFD study of section characteristics of Formula Mazda race car wings. Mathematical and Computer Modeling, vol. 43, no. 11-12, p. 1275-1287, D0I:10.1016/j.mcm.2005.03.011.

[10] Jensen, K. (2010). Aerodynamic Undertray Design for Formula SAE. MSc thesis, Oregon State University, Corvallis.

[11] Zvar Baskovic, U., Lorenz, M., Butala, V., (2014). Adiabatic flow simulation in an air-conditioned vehicle passenger compartment. International Journal of Simulation Modelling, vol. 13, no. 1, p. 42-53, D0I:10.2507/IJSIMM13(1)4.253.

[12] Bizjan, B., Orbanić, A., Širok, B., Bajcar, T., Novak, L., Kovač, B. (2014). Flow image velocimetry method based on advectiondiffusion equation. Strojniški vestnik - Journal of Mechanical Engineering, vol. 60, no. 7-8, p. 483-494, D0l:10.5545/svjme.2013.1614.

[13] Jošt, D., Škerlavaj, A., Lipej, A. (2014). Improvement of efficiency prediction for Kaplan turbine with advance turbulence models. Strojniški vestnik - Journal of Mechanical Engineering, vol. 60 , no. 2, p. 124-134, Dol:10.5545/svjme.2013.1222.

[14] Katz, J. (1995). Race Car Aerodynamics, Designing for Speed, Bentley Publisher, Cambridge.

[15] Katz, J. (2006). Aerodynamics of race cars. Annual Review of Fluid Mechanics, vol. 38, p. 27-63, D0l:10.1146/annurev. fluid.38.050304.092016.

[16] SAE International. 2016 Formula SAE Rules, from http://www. fsaeonline.com/content/2016_FSAE_Rules.pdf, accessed on 2016-04-08.

[17] McBeath, S. (2011). Competition Car Aerodynamics. Haynes Publishing, Somerset.

[18] Škerget, L. (1994). Fluid Mechanics. University of Maribor Technical faculty and University of Ljubljana, Faculty of Mechanical Engineering, Maribor, Ljubljana. (in Slovene)

[19] Wlicox, D.C. (1986). Multiscale model for turbulent flows. AIAA, 24th Aerospace Sciences Meeting, Dol:10.2514/6.1986-29. 